\title{
Integrasi Pembentukan Nilai Karakter Kemandirian Siswa Sekolah Dasar dalam Pembelajaran Matematika di Era Industri 4.0
}

\author{
Deysti Trifena Tarusu ${ }^{1 *}$, Zulela $^{2}$, Adi Apriadi Adiansha ${ }^{3}$ \\ ${ }^{1}$ Program Studi Pendidikan Guru Sekolah Dasar, Universitas Negeri Manado \\ ${ }^{2}$ Program Studi Doktor Pendidikan Dasar, Universitas Negeri Jakarta \\ ${ }^{3}$ Program Studi Pendidikan Guru Sekolah Dasar, STKIP Taman Siswa Bima \\ 1'deystitarusu@unima.ac.id, ${ }^{2}$ zulela@yahoo.com, ${ }^{3}$ adiapriadiadiansyah@gmail.com
}

\begin{abstract}
The importance of integrating the formation of the value of independence character in mathematics learning has a positive influence on the quality of education in Indonesia. The purpose of this qualitative study is to get input on how elementary school teachers are about integrating the value of independence characters in mathematics learning. This type of research uses a qualitative approach with interviews, observation, and documentation with the data validity test used is triangulation. The subjects of this study were classroom teachers and students at Buah Ati Elementary School in Bekasi Regency. The results of the study are 1) The value of the character of independence must be instilled in elementary schools, so students can appear aware of following the school rules and honesty with the students themselves; 2) The formation of the value of the character of independence must be given to children from childhood through education in schools, families, and communities; 3 ) Positive influence on the formation of the value of the character of independence in Mathematics Learning in the Industrial Age 4.0.
\end{abstract}

Keyword: Industrial Era 4.0, Character Value of Independence, Mathematics Learning.

Abstrak. Pentingnya integrasi pembentukan nilai karakter kemandirian dalam pembelajaran matematika memberika pengaruh yang positif terhadap mutu pendidikan di Inonesia. Tujuan dari penelitian kualitatif ini adalah untuk mendapatkan masukan tentang caranya guru sekolah dasar tentangmengintegrasikan nilai karakter kemandirian dalam pembelajaran matematika. Jenis penelitian ini menggunakan pendekatan kualitatif dengan wawancara, observasi, dan dokumentasi dengan uji keabsahan data yang digunakan adalah triangulasi. Subjek penelitian ini adalah guru kelas dan siswa Sekolah Dasar Buah Ati di Kabupaten Bekasi. Hasil penelitian yaitu 1) Nilai karakter kemandirian harus ditanamkan di sekolah dasar, sehingga siswa bisa muncul kesadaran dalam mengikuti aturan-aturan sekolah dan kejujuran pada siswa itu sendiri; 2) Pembentukan terhadap nilai karakter kemandirian harus diberikan kepada anak-anak sejak kecil melalui pendidikan di sekolah, keluarga dan masyarakat; 3) Pengaruh positif terhadap terbentuknya nilai karakter kemandirian dalam Pembelajaran Matematika di Era Industri 4.0.

Kata Kunci: Era Industri 4.0, Nilai Karakter Kemandirian, Pembelajaran Matematika

\section{PENDAHULUAN}

Pentingnya pendidikan karakter di kelas harus mampu mengembangkan kemandirian (Baxter Magolda, 2020; Carr, 2017; Yolcu, 2018) sebagai upaya dalam mengoptimalkan perilaku yang baik dari siswa. Penguatan pendidikan karakter memberikan integrasi terbentuknya nilai karakter kemandirian (Hadi, 2015; Mislia,
Mahmud, \& Manda, 2016) dalam proses belajar mengajar sangat penting. Jadi, penelitian tentang integrasi nilai-nilai karakter kemandirian dalam pembelajaran matematika (Fitriatien \& Mutianingsih, 2020; Hakam, 2018; Islami, 2016; Mulyono, Asmawi, \& Nuriah, 2018; Sulistyaningsih, Purnomo, \& Aziz, 2018) di Sekolah Dasar di era Industri 4.0 itu layak dan perlu dilakukan 
(Sulistyaningsih et al., 2018). Telah terbukti bahwa kemajuan pendidikan pendidikan karakter di Indonesia sangat bergantung pada hasil pendidikan pada generasi mudanya. Hasil pendidikan akan lebih bermanfaat bagi masyarakat, bangsa, dan negara jika lulusannya memiliki karakter yang baik nilainilai (Istiningsih, 2016; White \& Shin, 2017). Melalui pendidikan karakter, anak muda dapat dididik dan dibentuk sedemikian rupa generasi muda memiliki rasa nasionalisme, kejujuran, disiplin, dan yang baik tanggung jawab. Oleh karena itu, nilai karakter perlu diberikan kepada siswa sejak dini usia. Indonesia sebagai salah satu negara berkembang, jelas sangat tertarik untuk mengetahuinya bagaimana mengintegrasikan nilai-nilai karakter ke dalam proses pembelajaran di kelas.

Nilai Karakter kemandirian diintegrasikan ke dalam Proses Pembelajaran Matematika yang harus diberikan kepada siswa sejak usia dini (Dori, 2019; Sudirman, 2019). Nilai karakter kemandirian adalah sikap dan perilaku yang tidak bergantung pada orang lain dan berusaha untuk menggunakan semua energi, pikiran, dan waktu untuk mewujudkannya tujuan secara mandiri (Fitriasari, Tanzimah, \& Sari, 2018). Maka dipandang sangat penting diteliti mengenai integrasi pembentukan nilai karakter kemandirian siswa sekolah dasar dalam pembelajaran matematika di era industri 4.0.

Beberapa hasil penelitian menyatakan bahwa pendidikan matematika memuat nilainilai yang berpotensi untuk mendukung keberhasilan pembentukan karakter bangsa (Rudyanto \& Retnoningtyas, 2018), lebih lanjut (Hatip, 2019) mengatakan pentingnya pendidikan budaya dan karakter untuk lebih ditanamkan melalui pembelajaran pada peserta didik. Nilai-nilai budaya dan karakter apa saja yang perlu ditanamkan pada peserta didik yang sesuai dengan mata pelajaran matematika. Dari hasil pengkajian yang mendalam pada penelitian tersebut bahwa ditemukan kebahruan dalam penelitian ini sehingga menjadi penting dalam mengintegrasikan pembentukan nilai karakter kemandirian siswa sekolah dasar dalam Pembelajaran Matematika.

Pertanyaan Penelitian dalam penelitian ini yaitu: 1) Bagaimana integrasi terbentuknya nilai karakter kemandirian dalam pembelajaran matematika di era industri 4.0?; 2) Apa pengaruh terbentuknya nilai karakter kemandirian dalam pembelajaran matematika di era industri 4.0?

Tujuan Penelitian dalam penelitian ini yaitu: 1) Untuk mengetahui integrasi terbentuknya nilai karakter kemandirian dalam pembelajaran matematika di era industri 4.0?; 2) Untuk mengetahui pengaruh terbentuknya nilai karakter kemandirian dalam pembelajaran matematika di era industri 4.0 ?

\section{METODE}

Penelitian ini berdasarkan hasil penelitian dengan pendekatan kualitatif (Pieridou \& Kambouri-Danos, 2020; Shekhar, Prince, Finelli, Demonbrun, \& Waters, 2019) pada siswa sekolah dasar di Kabupaten Bekasi. Analisis dan interpretasi data dilakukan dengan analisis data kualitatif secara interaktif dan bertahan sampai akhir sehingga data sesuai untuk tujuan tersebut. Subjek penelitian ini adalah guru kelas dan siswa Sekolah Dasar di Kabupaten Bekasi. Objek dalam penelitian ini adalah karakter kemandirian pada siswa Sekolah Dasar. Sumber data yang dilakukan berupa: 1) Wawancara dan observasi dilakukan dengan guru; dan 3) Wawancara dan observasi dilakukan dengan siswa. Instrumen dalam penelitian ini adalah peneliti sendiri. Namun, setelah fokus penelitian menjadi jelas, dilakukan pengembangan instrumen penelitian dengan menggunakan pedoman observasi dan pedoman wawancara untuk memperoleh data karakter kemandirian pada siswa yang dilakukan di Sekolah Dasar. Teknik pengumpulan data dalam penelitian ini menggunakan wawancara, observasi, dan dokumentasi. Teknik analisis data yang digunakan dalam penelitian ini adalah analisis deskriptif. Analisis dilakukan dengan 
reduction atau mereduksi data, data display atau penyajian, dan conclusion drawing/verification. Uji keabsahan data yang digunakan dalam penelitian ini adalah triangulasi. Triangulasi yang digunakan adalah triangulasi teknik dan triangulasi sumber. Triangulasi teknik misalnya dilakukan dengan cara mencocokkan data yang diperoleh melalui teknik wawancara dengan data yang diperoleh dari hasil observasi. Triangulasi sumber dilakukan dengan cara mencocokkan data dari hasil wawancara sumber satu dengan sumber lainnya.

\section{HASIL DAN PEMBAHASAN}

Terintegrasi Nilai Karakter Kemandirian dalam Pembelajaran Matematika di Era Industri 4.0

Hasil temuan pendidikan karakter di kelas bahwa siswa menggunakan seragam dengan rapi; guru dan siswa masuk tepat waktu; ketika guru menjelaskan materi pembelajaran matematika siswa tidak ada yang berbicara. Nilai karakter kedisiplinan muncul ketika guru memberikan tugas kepada siswa untuk mengerjakan soal matematika. Dengan demikian, suasana belajar menjadi kondusif, kemudian semua siswa melakukan pekerjaan mereka secara mandiri, jujur, dan semuanya bekerja secara bertanggung jawab maka di sini nilai integritas muncul. Ketika bel berbunyi karena pelajaran berakhir, para siswa keluar dengan tertib, teratur, dan tidak menemukan siswa berkerumun di luar kelas. Selanjutnya, temuan nilai karakter kemandirian berdasarkan hasil wawancara dengan guru dan beberapa siswa dan dilanjutkan dengan peneliti pergi disekitar ruang kelas dan sekolah. Peneliti juga mengamati kebersihan, penataan sarana dan prasarana sekolah, dan lingkungan di luar sekolah.

Dalam pembelajaran matematika nilai karakter yang ditanamkan yaitu nilai karakter kemandirian, nilai karakter kemandirian terjadi ketika siswa mengerjakan soal-soal yang disuruh oleh guru. Para siswa mengerjakan secara mandiri untuk menyelesaikan dan memecahkan permasalah pada pembelajaran matematika dan siswa tidak bercanda pada saat mengerjakan tugas.

Kemudian cara guru dalam mengintegrasikan nilai karakter kemandirian dalam pembelajaran matematika dengan memberikan penugasan secara individu. Guru juga mengamati siswa mengerjakan tugas dengan jujur, bertanggung jawab, dan dengan cara yang disiplin. Tindakan guru untuk melatih siswa dalam menerapkan nilai karakter kemandirian melalui pertanyaan.

Hasil temuan di atas sesuai dengan tujuan penelitian yaitu terintegrasinya nilai karakter kemandirian dalam pembelajaran matermatika di era industri 4.0.

\section{Pengaruh Terbentuknya Nilai Karakter Kemandirian dalam Pembelajaran Matematika di Era Industri 4.0}

Peneliti mengunjungi kelas dengan melakukan wawancara dengan guru kelas dan beberapa siswa, kemudian peneliti pergi disekitar ruang kelas. Peneliti juga mengamati kebersihan, penataan sarana dan prasarana kelas, serta di lingkungan sekolah yang sangat bagus. Dalam pengamatan awal tentang pengaruh terbentuknya nilai karakter kemandirian dalam pembelajaran matematika di era industri 4.0 ini sebagai berikut: 1) Jenis nilai karakter yang ditanamkan oleh guru dalam prmbelajaran matematika yaitu kemandirian; 2) Guru mengintegrasikan nilai karakter kemandirian dalam pembelajaran matematika secara baik; 3) Kondisi lingkungan sekolah terlihat sangat bersih, tidak ada sampah yang berserakan, terlihat dikelas untuk tas dan sepatu diatur dengan sangat rapi.

Pengaruh terbentuknya nilai karakter kemandirian dalam pembelajaran matematika di era industri 4.0 ini diberikan kepada siswa sejak usia dini, baik secara langsung maupun tidak langsung. Pendidikan karakter telah diberikan kepada anak-anak sejak kecil dan dibantu melaui peran dalam keluarga. Melalui temuan tersebut bahwa terdapat pengaruh dalam terbentuknya nilai karakter 
kemandirian pada Pembelajaran Matematika di Era Industri 4.0.

\section{Pembahasan}

Nilai karakter kemandirian sangat diperlukan untuk diintegrasikan ke dalam proses pembelajaran matematika. Hal tersebut sejalan dengan beberapa peneliti bahwa pentingnya nilai karakter kemandirian untuk diberikan kepada siswa melalui pembelajaran di sekolah (Iftanti \& Madayani, 2019; Julia \& Supriyadi, 2018; Rianawati, 2017; Şahin, 2019; Suhartini, Sekarningrum, Sulaeman, \& Gunawan, 2019; Sulistyaningsih et al., 2018). Selanjutnya disana juga banyak cara yang bisa dilakukan untuk mewujudkan nilai karakter kemandirian di sekolah. Nilai karakter kemandirian tidak cukup untuk menjadi subjek pengajaran dan termasuk dalam rencana implementasi pembelajaran di sekolah. Namun, itu harus lebih dari apa yang dibutuhkan untuk diterapkan atau dipraktikkan. Penerapan nilai karakter kemandirian dapat dimulai dengan belajar untuk mematuhi peraturan sekolah, berdiskusi dengan teman dengan hangat dan disiplin yang ramah dan menegakkan di dalam dan di luar sekolah. Sekolah Dasar harus dapat membuat nilai karakter kemandirian ini berkembang dengan baik dan menumbuhkan nilai teladan dan banding oleh kepala sekolah, guru, dan staf sekolah di sekolah sehari-hari di sekolah dasar.

Nilai karakter kemandirian harus melibatkan semua minat pendidikan baik keluarga, sekolah, dan yang lebih luas masyarakat (Raptis \& Spanaki, 2013). Karena itu, langkah pertama adalah membangun kembali kemitraan yang akrab dan harmonis agar kita dapat mewujudkan kembali jaringan pendidikan antar lingkungan sekolah termasuk guru, keluarga, dan masyarakat.

\section{KESIMPULAN}

Berdasarkan hasil penelitian di atas, dapat disimpulkan sebagai berikut: 1) Nilai karakter kemandirian harus ditanamkan di sekolah dasar, sehingga siswa bisa muncul kesadaran dalam mengikuti aturan-aturan sekolah dan kejujuran pada siswa itu sendiri; 2) Pembentukan terhadap nilai karakter kemandirian harus diberikan kepada anakanak sejak kecil melalui pendidikan di sekolah, keluarga dan masyarakat; 3) Pengaruh positif terhadap terbentuknya nilai karakter kemandirian dalam Pembelajaran Matematika di Era Industri 4.0.

\section{SARAN}

Dalam penelitian ini mampu memberikan konstribusi tentang integrasi dalam pembentukan nilai karakter kemamdirian kepada siswa sekolah dasar dalam pembelajaran matematika, agar kiranya dapat dilaksanakan oleh guru atau pembaca. Penelitian ini memberikan informasi terpenting dalam meningkatkan mutu pendidikan dan sebagai landasan dalam proses pembelajaran

\section{UCAPAN TERIMA KASIH}

Penelitian ini merupakan hasil penelitian yang dilakukan oleh Calon Doktor Pendidikan Dasar Universitas Negeri Jakarta, sebagai ucapan terimakasih kepada Prof. Zulela MS.

\section{DAFTAR PUSTAKA}

Baxter Magolda, M. B. (2020). Developmental Complexity: A Foundation for Character. Journal of College and Character, 21(1), 14-20. https://doi.org/10.1080/2194587X.2019 .1696830

Carr, D. (2017). Virtue and Character in Higher Education. British Journal of Educational Studies, 65(1), 109-124. https://doi.org/10.1080/00071005.2016. 1224806

Dori, N. (2019). Education Towards Jewish Values in the Israeli State Preschool: Its Character, Essence, and Scope. Journal of Education and Training Studies, 7(8), 
18.

https://doi.org/10.11114/jets.v7i8.4317

Fitriasari, P., Tanzimah, T., \& Sari, N. (2018). Kemandirian Belajar Mahasiswa Melalui Blended Learning pada Mata Kuliah Metode Numerik. Jurnal Elemen, 4(1), 1. https://doi.org/10.29408/jel.v4i1.439

Fitriatien, S. R., \& Mutianingsih, N. (2020). Peningkatan Kemampuan Belajar Mandiri pada Mata Kuliah Operasional Riset melalui Self Regulated Learning Mosharafa : Jurnal Pendidikan Matematika Rata-rata Mosharafa : Jurnal Pendidikan Matematika. Mosharafa: Jurnal Pendidikan Matematika, 9, 95-106.

Hadi, R. (2015). The Integration of Character Values in the Teaching of Economics: A Case of Selected High Schools in Banjarmasin. International Education Studies, $8(7), \quad 11-20$. https://doi.org/10.5539/ies.v8n7p11

Hakam, K. A. (2018). Tradition of value education implementation in indonesian primary schools. Journal of Social Studies Education Research, 9(4), 295318.

https://doi.org/10.17499/jsser.98315

Hatip, A. (2019). Pembelajaran Matematika di Era Industri 4.0. Prosiding Seminar Nasional Pendidikan Matematika, 896906.

Iftanti, E., \& Madayani, N. S. (2019). Developing Joyful Story Sheets (JoSS): an Effort to Build Character for EYL Learners in Indonesia through Reading JoSS. Dinamika Ilmu, 19(1), 155-173. https://doi.org/10.21093/di.v19i1.1543

Islami, M. (2016). Character Values and Their Internalization in Teaching and Learning English at Madrasah. Dinamika Ilmu, 16(2), 279. https://doi.org/10.21093/di.v16i2.417

Istiningsih. (2016). Character Education of the Most Developed Countries in ASEAN. Journal of Education and ELearning Research, 3(1), 32-37. https://doi.org/10.20448/journal.509/20

\subsection{1/509.1.32.37}

Julia, \& Supriyadi, T. (2018). The Implementation of Character Education at Senior High School. SHS Web of Conferences, 42, 00085. https://doi.org/10.1051/shsconf/201842 00085

Mislia, M., Mahmud, A., \& Manda, D. (2016). The Implementation of Character Education through Scout Activities. International Education Studies, $9(6), \quad 130$. https://doi.org/10.5539/ies.v9n6p130

Mulyono, D., Asmawi, M., \& Nuriah, T. (2018). The Effect of Reciprocal Teaching, Student Facilitator and Explaining and Learning Independence on Mathematical Learning Results by Controlling the Initial Ability of Students. International Electronic Journal of Mathematics Education, 13(3), 199-205. https://doi.org/10.12973/iejme/3838

Pieridou, M., \& Kambouri-Danos, M. (2020). Qualitative doctoral research in educational settings: Reflecting on meaningful encounters. International Journal of Evaluation and Research in Education, 9(1), 21-31. https://doi.org/10.11591/ijere.v9i1.2036 0

Raptis, I., \& Spanaki, E. (2013). International Journal of Psychology and Educational Studies Teachers' Attitudes Regarding the Development of Socio-Emotional Skills in Elementary Schools in Greece ARTICLE INFO ABSTRACT. International Journal of Psychology and Educational Studies, 4(1), 21-28. https://doi.org/10.17220/ijpes.2017.01. 003

Rianawati. (2017). The Implementation of Education Character on Moral in MTsN (Islamic Junior High State School) 1 Pontianak in the Academic Year 2015/2016. Journal of Education and Practice, 8(9), 186-195. Retrieved from http://ezphost.dur.ac.uk/login?url=https ://search.proquest.com/docview/191335 
4679? accountid=14533\%0Ahttp://open url.ac.uk/ukfed:dur.ac.uk?genre=article $\&$ issn $=22221735 \&$ title $=$ Journal + of + Ed ucation+and+Practice $\&$ volume $=8 \&$ issu e $=9 \&$ date $=2017-01$ -

$01 \&$ atitle $=$ The + Implem

Rudyanto, H. E., \& Retnoningtyas, W. A. (2018). Integrasi nilai - nilai karakter melalui pembelajaran matematika di sekolah dasar. Prosiding Konferensi Ilmiah Dasar, 1(7), 34-43. Retrieved from

http://prosiding.unipma.ac.id/index.php /KID

Şahin, Ü. (2019). Values and Values Education As Perceived By Primary School Teacher Candidates. International Journal of Progressive Education, 15(3), 74-90. https://doi.org/10.29329/ijpe.2019.193. 6

Shekhar, P., Prince, M., Finelli, C., Demonbrun, M., \& Waters, C. (2019). Integrating quantitative and qualitative research methods to examine student resistance to active learning. European Journal of Engineering Education, 44(1-2), 6-18. https://doi.org/10.1080/03043797.2018. 1438988

Sudirman, S. (2019). The 21st-Century Teacher: Teacher's Competence Within the Character Education Framework Towards A Cultural-Oriented Development and Promoting Tolerance. International Education Studies, 12(8), 21. https://doi.org/10.5539/ies.v12n8p21

Suhartini, S., Sekarningrum, B., Sulaeman, M. M., \& Gunawan, W. (2019). Social construction of student behavior through character education based on local wisdom. Journal of Social Studies Education Research, 10(3), 276-291.

Sulistyaningsih, D., Purnomo, P., \& Aziz, A. (2018). Development of Learning Design for Mathematics Manipulatives Learning based on E-learning and Character Building. International
Electronic Journal of Mathematics Education, 14(1), 197-205. https://doi.org/10.29333/iejme/3996

White, R., \& Shin, T. S. (2017). Integrative character education (ICE): grounding facilitated prosocial development in a humanistic perspective for a multicultural world. Multicultural Education Review, 9(1), 44-74. https://doi.org/10.1080/2005615X.2016 .1276670

Yolcu, E. (2018). Teachers' Qualities and Self-Efficacy Perceptions in Character Education. Acta Didactica Napocensia, 11(3), $35-48$. https://doi.org/10.24193/adn.11.34.3.36 